\title{
On understandings of intention: A response to Wedgwood
}

\author{
Michael Haugh \\ Griffith University
}

\begin{abstract}
:
In a recent paper, Wedgwood (2011) launches a simultaneous defence of intention recognition and a critique of the alleged neglect of cognition in interactional approaches to communictive interaction. In this paper, I argue that this simultaneous critique and defence is deeply flawed on a number of counts. First, the "looser" notion of intention which Wedgwood proposes glosses over and even confounds various levels or types of intention, and for this reason is ultimately unfalsifiable. Second, in the course of his argumentation he confounds intention with intentionality and agency. Third, his claim that a focus on "local" intentions offers a more "fine-grained" and "explanatory analysis" is completely unwarranted in light of close examination of the data at hand. I argue that such an approach instead generates speculation which is analytically unproductive, and, does not account for the cognitively interdependent inferences that underlie conversational interaction in addition to traditional monadic inferential processes. It is concluded that further discussions about the requirements that interaction places on cognition, including the question of the place of intention and intentionality can be productive, but only if researchers are cognisant of the different ways in which intention has been defined, and also the different analytical work to which intention is put by scholars in pragmatics.
\end{abstract}

"The big question is not whether actors understand each other or not. The fact is that they do understand each other, that they will understand each other, but the catch is that they will understand each other regardless of how they would be understood"

(Garfinkel 1952: 367; cited in Heritage 1984: 119)

\section{Introduction}

In the introduction to a recent special issue of Intercultural Pragmatics on "Intention in pragmatics" I noted that raising questions about the place of intention in analyses of pragmatic phenomena can generate a range of incompatible responses, "ranging from 'believers' through to 'skeptics' (with perhaps not a few 'agnostics' in-between)" (Haugh 2008a: 106). I chose this analogy with discussions about religion quite deliberately. It seemed to me that while such discussions could become rather heated, they nevertheless could hold considerable value if they allowed us to deepen our understanding of meaning beyond what is said, social actions, relational and identity phenomena in communicative interaction, all of which seem to constitute pretty core business in pragmatics, at least as broadly construed. The flipside of the intrinsic value such discussions promise is that rather dogmatic or vitriolic responses can also eventuate. The special issue on "Intention in pragmatics" was offered largely as a response to Levinson's (2006a, 2006b) call to elevate Gricean intentions to the "heart" of cognition in interaction, as Levinson's call seemed, in my view, a somewhat reactionary move. While there can be no doubt that Grice's work on speaker meaning and conversational implicature has contributed immeasurably to the discipline of pragmatics, and it should be respected as such, my aim in editing this special issue was to stimulate discussion about both the characterisation and scope of intention in theorising pragmatics. A range of scholars with very different 
understandings of intention and the role it plays in the analysis of meaning, and communication more broadly, contributed to the special issue. My hope was that in recognising intention does different work in different arms of pragmatics we could start work on comparing and analysing those differences in a way that moved our understandings forward in a productive manner. I also argued that no matter what our views might be on the place of (Gricean) intentions, "there remains a need to account for the cognition that underlies interaction" (Haugh 2008a: 102).

It is against this background that I wish to respond to a recent article published by Wedgwood (2011) that launches what appears to be, on the one hand, a withering critique of "interactional" approaches to communicative interaction in claiming that such approaches make "implicit appeals to the very individual-, utterance-, and intention-based reasoning that they claim to reject" (p.523), and, on the other hand, a spirited defence of the capacity of "cognitive" approaches to account for the "contingencies of actual communicative interaction" (p.525). He focuses on work by Arundale (2008) that was published as part of the aforementioned special issue, as well as papers by myself that were published elsewhere (Haugh 2008c, 2009) as the specific target for his critique of "interactional" approaches, and his concurrent defence of intention recognition as being at the heart of communication and "cognitive" approaches more broadly.

Arundale (this issue), in his response, addresses the flaws in Wedgwood's arguments in relation to understandings of communication. He focuses on Wedgwood's unwarranted attempt to create a "strawman", namely, that cognitive and "discourse-level" pragmatics are in conflict, which arises, in turn, from his complete misrepresentation of the "necessary but not sufficient" argument that we both made in relation to the place of individual and utterance-level phenomena in analyzing communicative interaction. He also critically considers Wedgwood's claim that the "dynamism, interaction, and emergence of meaning... are wholly compatible with, indeed intrinsic to, a fully worked out individual-based pragmatic theory"

(Wedgwood 2011: 520). Against the background of Arundale's (this issue) response, I would like to focus here specifically on the issue of intention and its place in the analysis of communicative interaction.

My argument is that the simultaneous critique and defence that Wedgwood's (2011) paper attempts in relation to intention is deeply flawed on a number of counts. I would like to note from the outset, however, that my response here is in no way intended as a final word on this issue, but rather is modestly offered as one step forward in unraveling the complex issues that any discussion of the place of intention in pragmatic theorisation entails. I start in that vein, in section two, by first giving a brief overview of the different ways in which intention has been defined, and also the different analytical work to which intention is put by scholars in pragmatics. I then compare this to the "looser" notion of intention which Wedgwood proposes, arguing that his notion of intention glosses over and even confounds various levels or types of intention, and for this reason is ultimately unfalsifiable. I then consider Wedgwood's arguments in relation to the alleged centrality of intention in communication in section three. I suggest here that Wedgwood's "catholic and relatively weak notion" of intention becomes simply incoherent, as he confounds intention with intentionality and agency in the course of his argumentation, and so unwittingly conflates very different understandings of intention. I then move in section four to consider the vexed issue of "locating" intentions in communicative interaction, and argue that Wedgwood's claim that a local intention-based analysis of conversational interaction offers a more "fine-grained" and "explanatory analysis" is completely unwarranted in 
light of close examination of the data at hand. I reiterate that such an approach generates speculation which is analytically unproductive, and, does not account for the cognitively interdependent inferences that underlie conversational interaction in addition to traditional monadic inferential processes. I conclude in section five by suggesting that it is only by employing multiple methodological perspectives to carefully unpack our multiple (and sometimes competing) understandings of intention, intentionality and other relevant cognitive states, as well the analytical work such notions do, that we will further our understanding of cognition for interaction, which Levinson (2006a, 2006b) has quite rightly called for, in more productive ways.

\section{On understanding intention(s) and intentionality ${ }^{1}$}

It is considered axiomatic by many in pragmatics that communication involves speakers expressing a particular type of complex intention through utterances, and addressees recognising and attributing those intentions to speakers through inferences. It is most commonly claimed that this intention is of the kind originally proposed by Grice (1957), namely, the speaker "intended the utterance of $x$ to produce some effect in an audience by means of the recognition of this intention" (p.385), or some modified version of this. This type of intention is variously termed a Gricean, communicative, or meaning intention. It is also generally accepted, largely following the seminal work of Grice, that this communicative intention involves at least one layer of reflexivity, namely, that embedded within a second-order communicative intention is a first-order informative or referential intention. In other words, a communicative intention involves a first-order intention (i.e. to intend to inform or represent something) which is embedded in a second-order intention (i.e. to intend that this first-order intention be recognised by the addressee). ${ }^{2}$ It has also been argued that in some instances first-order intentions are not embedded in a second-order communicative intention but rather in a second-order "manipulative" or "covert" intention (Németh T. 2008; Taillard 2003), in order to account for instances where speakers want to inform addressees of something without necessarily being held as intending that. But no matter whether we are talking about communicative or covert/manipulative intentions, it is generally accepted that such intentions constitute a priori mental states that proceed the formulation of an utterance (Gibbs 1999). ${ }^{3}$ There are two key points to consider when conceptualising communicative intentions in this way. First, communicative intentions are not the only kind of intention potentially relevant to the analysis of communicative interaction. Second, the notion of intention is deployed for a range of different analytical purposes in pragmatics, which has implications for the extent to which communicative intentions are relevant for the analysis of conversational interaction. As we shall later see, the first point is barely addressed by Wedgwood (2011), while the latter is completely neglected.

\subsection{On types of intention}

Communicative intentions are clearly not the only kind of intention potentially relevant to the analysis of communicative interaction. According to Searle (1983), they lie within the broader category of prior intentions, a category he proposed in order to contrast this kind of intention with intentions-in-action or "motor intentions", which are hypothesised to constitute "the proximal cause of the physiological chain leading to overt behaviour" (Ciaramidaro et al 2007: 3106). Putting aside the issue of "motor intentions" for now, it has become evident that prior intentions are not 
exhausted by communicative or manipulative intentions. A range of other different types of prior intentions have been proposed, including higher-order intentions (sometimes also called future-directed or prospective intentions) (Bratman 1999), private intentions (Airenti, Bara and Colombetti 1993), and we-intentions (Searle 1990) (cf. Bara 2011: 450-451). We-intentions are generally contrasted with I(ndividual)-intentions. Prior intentions that lie solely in mental space of the speaker (i.e. I-intentions) can be categorised relative to two dimensions: (1) private versus social intentions, and (2) proximal/recursive versus future-directed/prospective intentions.

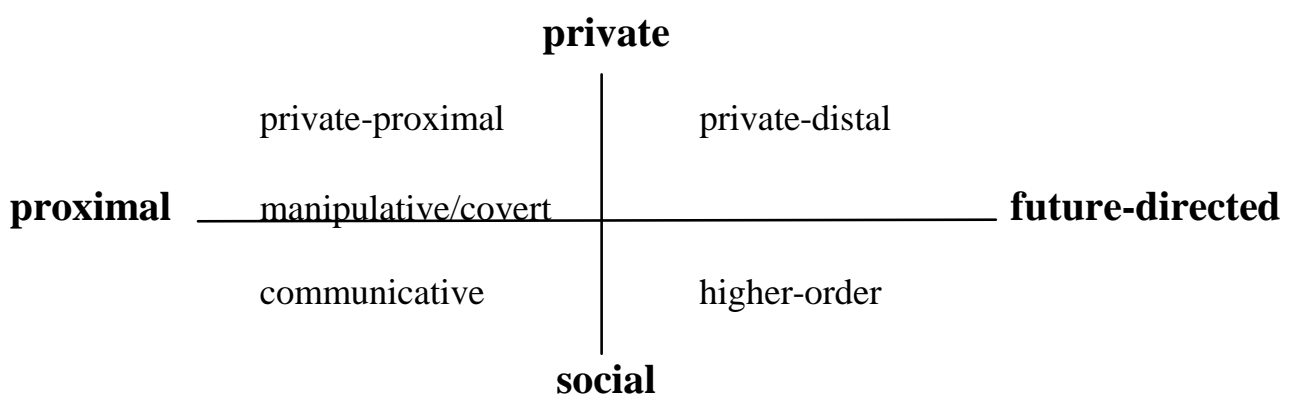

Figure 1: Types of prior I-intentions

Private intentions (whether proximal or distal) involve the representation of a goal that ostensibly involves only the speaker. However, since the pursuit of private goals by individuals (e.g. the addressee reaching into her purse to pay for coffee) may enter into the attended context of other individuals (e.g. another individual concerned about who is going to pay for the coffee), inferences about ostensibly private intentions may nonetheless be relevant to the formulation of social intentions (Haugh and Jaszczolt 2012: 99).

Higher-order intentions are proposed to account for the planning of future social actions, activity types and the prospective goals of speakers that involve other individuals, as opposed to proximal intentions, such as communicative intentions, which are directed at current utterances or actions in the present moment. While it has been traditionally assumed that meanings, including implicatures, can be analysed solely in terms of communicative intentions, this view is difficult to reconcile with decades of work demonstrating that meaning arises in the course of "delivering" actions (Austin 1962; Levinson forthcoming; cf. Wedgwood 2011: 540, fn.13), particularly in the case of communicative interaction. Recent work by relevance theorists (Ruhi 2007) and neo-Gricean theorists (Levinson 2011), for example, has illustrated the analytical import of higher-order intentions for the analysis of (speaker) meaning. On their view, then, it makes no sense to divorce consideration of higherorder intentions (potentially) relevant to the analysis of social actions, activity types and the like from a consideration of communicative intentions if they are argued to be relevant to the analysis of utterance-meaning.

In contrast to I-intentions, we-intentions are hypothesised to account for the fact that underlying cooperative activities, such as playing football, is a primitive form of intentionality, namely, "we intend that we perform act A" (Searle 1990: 407). ${ }^{4}$ While some have argued we-intentions (or shared intentions) can be reduced to Iintentions supplemented with mutual beliefs (Bratman 1999; Pacherie 2007; Tuomela and Miller 1988), this has proven to be cognitively implausible due to the strenuous requirement for sharedness (Becchio and Bertone 2004: 127-128). The essence of the 
argument behind we-intentions is that individual members of a team I-intending, for example, particular elements of a pass play does not straightforwardly result (in a summative sense) to the collective action of a pass play. This is because, as Haugh and Jaszczolt (2012) argue, in the course of we-intending engagement in that kind of collective activity, "each team member's I-intentions are responsive to their perceptions of the I-intentions of other team members, meaning, in other words, that the I-intentions of team members are both afforded and constrained by the I-intentions of others in making the pass play" (p.100). It has been suggested that we-intentions may also be relevant to the analysis of communicative interaction, since it also involves a kind of collective action (Clark 1996; Gibbs 1999; Searle 1990: 415).

However, while the notion of we-intentions has been proposed as a means of solving the problem of accounting for conversational interaction as a fundamentally joint activity, there are a number of challenges facing such a proposal. One problem is that we do not know enough about we-intentions yet, a consequence perhaps of their inherent ontological ambiguity as to whether they are prior or post facto/emergent mental states (Haugh 2008c: 53-54). We also do not yet understand well the mechanisms by which they could come to be shared between two or more people in the first place. The fact that we-intentions also entail a narrow focus on achieving particular aims or goals is another possible limitation of the notion of we-intentions, especially when one considers that the intentional cognitive states-processes which underpin collective activities are much broader in scope, potentially encompassing beliefs, expectations, (joint) commitments, attitudes and the like.

It is important to note that many of these different types of intention were originally proposed as theoretical constructs to be deployed for analytical purposes by philosophers. However, it is apparent that many researchers in pragmatics are now committed to the assumption that such intentions constitute real cognitive states. Indeed, there is evidence emerging from experiments in neuroscience investigating the neural correlates of our ability to attribute mental states that supports drawing the theoretical distinctions I have discussed here (Bara 2010, 2011; Noordzij et al 2010). ${ }^{5}$ Some might therefore claim that such studies "prove" that the attribution of communicative (and other types of) intentions lies at the core of cognition in communicative interaction. However, I would caution that such work only lends support in principle to drawing distinctions between private versus socially-oriented or distal versus prospective mental state-processes, for instance. It does not constitute evidence of the existence of particular putative intentions per se. Labelling different neural activity as evidence of representations of or inferential work about various kinds of intention involves an underlying assumption that such work does not directly address, namely, that we are dealing with intentions here and not something else.

\subsection{On uses of intention in pragmatics}

A second consequence of the received understanding of communicative intentions as a priori mental states that proceed the formulation of an utterance is that it is assumed, albeit often tacitly, that these intentions are necessarily directed at an "object", and so are "intentional" in the broadly philosophical sense of the ability of the mind to represent objects, properties or states of affairs (Haugh and Jaszczolt 2012: 88). While intentions and intentionality are often confounded, they are in fact distinct analytical concepts. A key claim in relation to the latter is that certain mental states are intentional in the sense that they are about something, that is, they have an object. Intentional mental states include beliefs, desires, wants, thoughts, feelings, attitudes, 
and, of course, intentions, among other things. Intentional mental state-processes include attention/attending, perceptions/perceiving, inferences/inferring,

evaluations/evaluating, interpretations/interpreting and the like. It is an open question just how "conscious" intentionality might be. One might argue that while intentional mental states may not always be salient or consciously entertained by individuals, they are nevertheless always available for introspection. On the other hand, one might argue that the default or routine nature of many instances of such mental statesprocesses might preclude their conscious availability at times. It would thus be fair to conclude that intentional mental states, including arguably intentions, are marked by epistemological ambigiuity as to their degree of conscious recall.

A corollary of the assumption that certain mental states, and thus linguistic acts, are intentional (Haugh and Jasczcolt 2012: 92-93), is the deontological notion of intention, and intentionality more broadly. This is generally framed in the literature as either speaker or joint commitment (Brandom 1994; Morency, Oswald and de Sassure 2008; cf. Garmendia 2011), or, alternatively, accountability (Garfinkel 1967; Sacks [1964]1992: 4-5). The former notion is defined in various ways, including the degree to which an individual is held to be committed to the truth conditions of an utterance (Searle 2007: 33-34), or two or more individuals are held to be jointly committed to undertaking a collective action (Gilbert 2009), for instance. The latter refers to the ways in which individuals hold themselves and others normatively accountable for the meanings and actions that arise from what is said (and done); for instance, through topicalising intentions (Haugh 2008b, 2008c; Edwards 2008). Since speaker commitment or accountability is inherently a discursive construct, it is always open to dispute. It is in this sense that we can talk about the "negotiation" of meaning in interaction. However, the deontological sense of intention (and intentionality) is not limited to such explicit disputes, but is instead an ever-present working assumption of conversational interactants, which underlies the ways in which we normatively "make available" meanings through what we say, and are held committed to or accountable for making such meanings available, even when it might not match our claimed intentions (in the folk, discursive sense).

It is worth noting that folk or intuitive senses of intend/intention (Gibbs 1999: 22-23; cf. Bara 2010: 76-77), which involve describing what oneself or others want to achieve by doing or saying something (i.e. as goal-oriented/directed), or classifying actions as being done with the speaker's awareness of the implications of them (i.e. as deliberate), among other things, are to some extent analogous to higher-order intentions. They differ, however, in that folk senses of intention are discursive constructs, which arise through evaluations by others of the speaker's awareness of the implications of what he is saying or doing, and/or evaluations of what the speaker is aiming to do through the utterance (or behaviour more broadly). In other words, they involve a moral dimension (Knobe 2010). Higher-order intentions, on the other hand, are assumed to be rooted in some kind of cognitive reality, and so it is presumed that such mental states are causative of speakers actions, being accomplished through the workings of motor intentions (the latter of which are cognitive state-processes but not representational or conceptual in nature).

While I have only briefly outlined here some of the ways in which intention (and intentionality) are discussed in the literature it is quite apparent that the notion of intention is deployed for a range of different analytical purposes in pragmatics. Intention can be used definitionally in the analysis of (speaker) meaning without any necessary commitment to its psychological reality, and in that sense constitutes a theoretical construct only. Intention may also be assumed to constitute a crucial 
component of the cognitive activities involved in communicative interaction, and thus in that sense is a working analytical construct, although in cognitive pragmatics a range of different types and levels of intentions are generally considered important for any analysis. Finally, intention can be understood as a discursive construct, where the focus is on the normative work intention in the folk sense does in communicative interaction. My view is that it is important to distinguish between these different uses of the concept of intention and intentionality when considering the putative place of communicative intentions in communicative interaction.

\subsection{On Wedgwood's understanding of intention}

The evident complexity of thinking about intentions and intentionality, and the different ways in which it is deployed in the literature contrasts markedly with Wedgwood's (2011) approach. He claims that reasoning about a "local" or "utterancelevel" intention, which he formulates as simply "what the speaker wants to get across' through a particular utterance, at the point at which it is formulated" (p.526), can successfully account for communication. He contrasts "local" intentions with "wider" intentions, which he characterises rather loosely (and indeed with pernicious circularity) as "the wider intentions that may be attributed to an individual's behaviour in a certain situation" (p.526), and goes on to make the claim that "intention attribution models do not, and need not, aspire to explain these wider intentions directly" (p.526). Finally, he asserts that "local" intentions need not be fully "conscious" and in some instances may be "subconscious and/or vague" (p.527).

The first thing one might note about Wedgwood's characterisation of intention is that it is strikingly simplistic. Although he purports to be "defending" cognitive approaches, his exposition of intention hardly does such approaches any justice at all. And while claiming that "local" intentions underlie all the utterances that constitute a communicative interaction, Wedgwood does not provide any account of how such intentions are realised in communication. More problematically, he does not address how his notion of "local" intention might figure in a model of utterance interpretation, let alone a model of communication. He thus does not explain how individuals might come to share, even if only partially, understandings of these intentions, but rather seems content to simply assert that addressees figure out these intentions from what speakers say. This completely glosses over the complex reflexivity required of an intention-based explanation of communication.

Let us consider, for instance, Levinson's (1983) example of an implicature that arises in the context of the following request sequence.

1 A: Hullo I was wondering whether you were intending to go to Popper's talk this afternoon

2 B: Not today I'm afraid I can't make it to this one

3 A: Ah okay

4 B: You wanted me to record it didn't you heh!

5 A: Yeah heheh

6 B: Heheh no I'm sorry about that... (Levinson 1983: 358)

While Haugh (2009: 94-97) focused on the temporal, ontological and epistemological ambiguity that surrounds A's alleged communicative intention underlying his utterance in turn 1, we could nevertheless hypothesise (although based 
on a post facto analysis) that $\mathrm{B}$ did indeed attribute a communicative intention to A upon hearing his utterance in turn 1. Specifically, that A was intending to check whether it would be possible for B record Popper's talk for him (i.e., what could be said to be implied by A in turn 1). However, in order for B to infer this communicative intention, he would necessarily also have to make an inference about A's (possible) higher-order intention, namely, his intention to make a request, as it is only in the context of the latter that the former inference would be plausible. One might also add that this presupposes, in turn, that $\mathrm{A}$ and $\mathrm{B}$ are we-intending engagement in (or are jointly committed to) the possibility of getting something done (i.e. arranging a recording of the talk) as opposed to simply exchanging information about each other's activities, since that higher-order intention would, in turn, only be consistent with the former interpretive frame. As Haugh and Jaszczolt (2012) note, this means that any putative "communicative intention of $\mathrm{A}$ is embedded within his higher-order intention, with both intentions arguably being further embedded within a we-intention" (p.101). It is this requirement for multiple types of prior intentions to be embedded within each other that leads to the temporal and ontological ambiguity that Haugh $(2008 \mathrm{c}, 2009)$ originally noted in relation to the place of communicative intentions in analysing implicatures. Such an analysis directly contradicts Wedgwood's (2011: 526) claim that "wider" intentions are indicated through recognition of "local" intentions. It suggests the very opposite, namely, that in many cases, "local" intentions could only be attributed in instances where "wider" intentions (which might more properly be termed higher-order intentions, private intentions, we-intentions) are also at play.

The second thing one might note about Wedgwood's (2011) characterisation of intention is that it is inconsistent. He suggests that the ambiguities surrounding communicative or "local" intentions can be resolved by admitting the possibility of subconscious or vague intentions (pp.527-528). One problem is that Wedgwood conflates in his argument for subconscious or vague intentions the issues of the relative (in)determinacy of intentions (in the folk sense) and the (in)determinacy of meaning, when they are in fact analytically distinct matters. As Wilson and Sperber (1986) quite rightly pointed out, pragmatic meanings such as implicatures vary in their degree of strength. Speakers may be held more or less committed to the truth of particular implicated assumptions or conclusions, for instance, and the conceptual or informational content of implicatures may also vary in its degree of determinacy. But the indeterminacy of various types of pragmatic meaning should not be conflated with the degree of "vagueness" of the speaker's alleged intention (Haugh in press a). It may be quite clear to the addressee, for instance, that the speaker does not intend to answer a question more clearly when discussing delicate matters. In such cases, the meaning representation itself may be fairly indeterminate, but the speaker's intention may be regarded as quite clear, if indeed the participants orient to it. In other instances, the speaker's intention to mean something may indeed by evaluated as vague by others, yet the meaning representation itself may be quite determinate. The indeterminacy of meaning therefore cannot explain in and of itself the alleged ambiguity of putative communicative or "local" intentions.

Another problem is that Wedgwood generates theoretical incoherence in his own account through his move to admit subconscious or vague intentions. He claims that "the key role for intentions in a broadly Gricean framework is not to "guide or motivate speakers', but to trigger and guide the act of communication" (Wedgwood 2011: 527), yet subsequently argues, contra to his earlier claim, that intention should be broadened to include "subconscious motivations" (p.530, emphasis added). He 
offers as an example of this, the case of communicative accommodation where a speaker's accent can subtly converge with or diverge with another interlocutor's accent as a sign of solidarity or distance. From this example it appears that Wedgwood is arguing that speakers may have "subconscious intentions" about which addressees may make "subconscious inferences", and that while neither the speaker nor the addressee are aware of this, it nevertheless constitutes communication. The problem here is that proposing a notion of subconscious communicative intentions is clearly paradoxical (Bara 2010: ix, 87). It is also ultimately empirically unfalsifiable. If a "local" intention can, as Wedgwood (2011: 528) appears to claim, arise in relation to something that the speaker is not aware he or she wishes to get across, and is not sure what it is that he or she wants to get across, and the addressee is also not aware that he or she is attributing an intention to the speaker to get across something about which the speaker is not sure what he or she wants to get across, one wonders how one could possibly demonstrate either the presence or absence of such intentions? One also wonders if there is any inherent value in attempting to do so, except, perhaps to mount a defence of an approach to communicative interaction that attempts to pin everything to speaker intentions.

I have argued in this section that Wedgwood's (2011) approach to intention is markedly out of step with other approaches to intention in pragmatics, and cognitive pragmatics specifically. He neglects the different types and uses of intention in pragmatics in postulating an intuitive but ultimately incoherent and empirically unfalsifiable notion of "local" intention. While he calls for a "highly nuanced view of the role of intentions in communication" (p.528), the simplistic notion of intention he defends does not do justice to such a call. In the following section, putting aside the problems evident in Wedgwood's (2011) account of intention, I will consider the arguments that he forwards in support of his claim that intentions are "ineliminable from the theory of communication" (p.517), and, in particular, are "central to the analysis of "sociocultural-interactional" features of dialogue" (p.537), in order to illustrate the flaws in his line of argumentation.

\section{On the "centrality" of intentions in communicative interaction}

Wedgwood (2011) makes two conjoined assertions in regards to the centrality of intentions in communication. He first asserts that intentions are (1) "indispensable in the theory of how we communicate", followed immediately by the claim that (2) "in the absence of some form of intention, speakers simply have no basis on which to formulate utterances" (p.530). These two assertions are placed as if one supports the other, but therein lies the essential problem with Wedgwood's argument: his lack of recognition that there are different types of intention, including most crucially higherorder/folk intentions, which are not of the same order as communicative or "local" intentions, and a lack of awareness that there are different uses to which intention is put to work in pragmatics (including intention/intend in the folk sense). He offers three related lines of argumentation to bolster his claims: (1) all utterances must be "motivated" by something, and that something is "local" intentions, (2) miscommunication can only be explained with respect to "local" intentions, and (3) interactional accounts cannot do without appeals to "local" intention-based reasoning. Close examination of the arguments that Wedgwood offers, however, illustrates how different treatments of intention are confounded in the course of his argumentation, in particular, between intention and intentionality more broadly, and between intention as an analytic as opposed to a discursive concept. 
The first line of argumentation draws on the idea that all utterances are "motivated" and thus that "intentions" must underlie all communication, and indeed are "definitional of the kind of communication humans engage in" (Wedgwood 2011: 531). This idea is recycled a number of times, but the following excerpt gives an idea of the underlying thrust of Wedgwood's argument:

We do not produce utterances randomly, with no sense of the effects they might have - and if anyone did this, it would clearly not constitute communication. Utterances are motivated, even when the motivation is subconscious or relatively hard to define. Accordingly, they do not license an unrestricted range of interpretations... Thus, the intention behind an utterance is a crucial motivation and guide to the process of interpretation, as well as production (Wedgwood 2011: 530).

The problem here is that Wedgwood confounds the intentionality of linguistic acts with the more limited notion of intention. We are generally held accountable for the utterances we produce and the meanings, actions, evaluations and so on which they give rise to (although this stricture might be somewhat loosened in some circumstances, such as when the speaker is evidently drunk or otherwise mentally incapacitated). An implicature, for instance, is by definition an unsaid meaning for which a speaker is held committed to, or accountable for - as opposed to say a perception of or inference about a person, for which we cannot always be held accountable (Haugh in press b). The question is why a speaker can be held committed to, or accountable for that implicature even though it has not been expressed. The answer is not because a speaker is always held to intend what has been implied (see also Horn 2012), but rather lies in the assumed intentionality of linguistic acts and the presumed agency of speakers. Linguistic acts are held to be directed, to be about something, and we are presumed to be exercising our agency in producing them. This is why we are held accountable for producing them. How addressees figure out what these linguistic acts are about is a separate question. But at this point it is worth remembering that intentionality covers a much broader spectrum than simply intentions, and thus so does agency. To argue that all utterances must be "motivated" and thus intentions underlie all communication entirely misses the crucial distinction between intention and intentionality, and the fact that speaker accountability arises as a consequence of presumptions about intentionality and agency, not intentions as narrowly construed by Wedgwood.

Indeed, once we consider the broader notions of intentionality and accountability, a narrow focus on intentions in communicative interaction seems somewhat unwarranted. It is worth remembering that we inherited this focus on communicative intentions from Grice (1957) who was originally interested in speaker meaning. However, we don't just mean things in interaction (putting aside the issue of whether one might define that solely in terms of putative speaker intentions), we also do things, we think things, we believe things, we feel things, we evaluate things and so on and so forth. And participants in communicative interactions are clearly interested in those putative intentional states as well. A singular focus on intention/intending seems to unnecessarily narrow the scope of our analytical interest in conversational interaction. It is for this reason that I called for a consideration of intentionality more broadly in the analysis of communicative interaction (Haugh 2008c, 2009, 2012).

In light of that, Wedgwood's (2011: 528) attempt to boil down all "sociocultural-interactional" features of dialogue, such as "to appear polite", "to 
maintain social relationships" or "to project a certain attitude or mood" to recognition of intentions seems totally unnecessary. Why should one attempt to explain such interpersonal phenomena relative to "local" (whether vague or not) intentions in the first place? The addressee can make inferences about the speaker's attitudes towards or evaluations of the addressee (or his or her relationship with speaker) in such cases without having to entertain inferences about the speaker's intentions, no matter how we define them. While there is no doubt inferences about the speaker's (communicative, higher-order, folk) intentions could arise in certain situations, there is simply no requirement that the addressee make any inferences about the speaker's intentions here, subconscious or not. While there is not sufficient space here to elaborate, particularly given the massive literature on "sociocultural-interactional" features of dialogue, a consideration of how the definition of impoliteness has changed in light of empirical study proves a case in point. While impoliteness was initially understood as a kind of intended/intentional face attack (e.g. Culpeper 2005: 38), the most comprehensive study of impoliteness to date has demonstrated that it is sustained by "expectations, desires and/or beliefs about social organisation", and that while "understand[ing] a behaviour to be strongly intentional or not" can "exacerbate how offensive an impolite behaviour is taken to be" the latter is not critical to it (Culpeper 2011: 23). In other words, it is intentional states other than intentions, such as beliefs, desires, expectations that arguably prove critical to our understanding of impoliteness. $^{6}$

The second line of argument draws on the idea that in some cases "misinterpretations" arise, for instance, speakers may claim they did not "intend" what they have been taken by others to mean by a particular utterance, and thus that "intentions" are central to any account of successful and unsuccessful communication.

To define misinterpretation requires reference to conflict with the speaker's intentions...It is thus clear that language users rely on the notion of speakers' intentions to distinguish successful from unsuccessful communication... and that this distinction is important, given the potentially significant practical, social and emotional consequences of having unintended meanings attributed to one's utterances (Wedgwood 2011: 532).

The problem here is that Wedgwood confounds an analytic with a discursive understanding of intention. An analytic understanding of intention either treats it as a theoretical construct for the analysis of speaker meaning, or presumes it has psychological reality as a casual intentional state in the production of actions or in utterance processing (the latter of which constitutes Wedgwood's position). A discursive understanding of intention, on the other hand, treats it as a construct emerging through discourse that is used in folk teleological explanations of "how we communicate", and is thus open to discursive dispute (Edwards 2008; Haugh 2008b; Haugh and Jaszczolt 2012: 109-111), including the "strong reactions" that speakers might have when "accused of meaning something they didn't intend" to which Wedgwood (2011: 532) makes reference. However, an examination of how intention/intending and so on are treated discursively by participants does not constitute evidence of the psychological reality of an analytic notion of intention in utterance processing. Instead, a discursive understanding of intention involves a deontological perspective that inevitably engenders considerations of normativity in utterance interpretation, including (disputes about) what interpretation(s) a particular utterance makes available. It is worth remembering that in defending what is "meant" 
by a particular utterance (or longer discourse unit), speakers do not only appeal to what they intended, but may also invoke word meaning, contextual factors, sociocultural understandings and so on and so forth (Haugh 2008b). Indeed, repair in general involves much more than troubles in understanding alleged speaker intentions, contra to Wedgwood's (2011: 532) claim, as any cursory examination of the literature on repair in conversation analysis would indicate (Schegloff 1987, 1991, 1992). For these reasons, appeals to one's intention (a discursive notion) in defending what one really meant cannot be treated as direct evidence that "local" intentions (an analytic category) underpin all utterance production and interpretation.

The third line of argumentation is that "interactional" accounts are not able to explain utterance interpretation without implicit appeals to the "intention-based reasoning that they claim to reject" (Wedgwood 2011: 523). I will go on to argue in more detail in the following section that such a claim is vacuous. However, it is nevertheless worth considering further the kinds of cognitive states and processes that might underlie communicative interaction, since this is an obvious area of common interest between "cognitive" and "interactional" approaches, contra Wedgwood's misrepresentation of my position and Arundale's (this issue). But perhaps to put it more precisely, the question is what cognitive states and processes are required to account for communicative interaction? And are intentions always necessarily postulated in such an account?

Given that there are different uses of intention in interaction (including the discursive co-construction of intention/intend in the folk sense), it seems trivial to claim that a theory of communication must deal with the fact that speakers do "at times have particular motivations or plans underlying what they are saying, or that recipients do not at times make inferences about what has motivated the speaker to say something" (Haugh 2009: 93, emphasis added). Of course it does, because we evidently do have interactional "goals" or "motivations" that we do entertain at certain times when communicating with others. And I am certainly not unsympathetic to the idea that "goals" or "motivations" may sometimes be subconscious (Bargh and Williams 2006; Evans 2008; Uleman, Saribay and Gonzalez 2008). In this sense, I would agree that any analysis of communicative interaction must account for the interactional "goals" we might have at times. We can conceptualise interactional "goals" or "motivations" as higher-order intentions (from a cognitive perspective) or as folk intentions (from a discursive perspective). However, as the discussion in the previous section has indicated, a folk or higher-order intention is not of the same order as a communicative intention or Wedgwood's "local" intention. Thus, while I would agree that we should analyse higher-order or folk intentions (depending on one's perspective) in communicative interaction when there is empirical evidence that these are oriented to by participants, this does not mean that we should presume such "goals" always guide communication.

However, to allow for the analysis of higher-order/folk intentions in conversational interaction does not automatically lend support to Wedgwood's (2011) second claim that "local" intentions are the basis for formulating (and interpreting) utterances. Indeed, there is good reason to be cautious about the claim that communicative or "local" intentions are always the basis of utterance interpretation. One is the burgeoning literature on default interpretations, namely, "a level of systematic pragmatic inference based not on direct computations about speakerintentions but rather on general expectations about how language is normally used" (Levinson 2000: 22). These are hypothesised by Levinson $(1995,2000)$ to help participants overcome the speech processing bottleneck. There is a growing 
experimental literature, however, indicating that default inferences are not computed locally from particular lexical items (see, for instance, Breheny, Katsos and Williams 2006; Chevallier et al 2008; Noveck 2001), but rather arise at the level of utterances and beyond (Jaszczolt and Allan 2011; Garret and Harnish 2007, 2009; Geurts 2010). Such inferences are "directed" at sociocultural (or cognitive) defaults and so are intentional in the philosophical sense. Speakers are thus held to be committed to, or accountable for such default meanings, but since the whole raison d'etre of defaults is to avoid (complex) calculations about speaker intentions, such work evidently undermines Wedgwood's (2011) claims about the centrality of "local" intentions.

Recent work by scholars working from various "cognitive" perspectives also indicates that this assumption about the centrality of "local" intentions may not be warranted. Gil (2011), for instance, draws from empirical work in neurocognitive linguistics in arguing that "there are many representations that are not intended by the speaker but inferred by the hearer on the basis of the speaker's verbal behaviour" (p.34), and thus "human verbal interaction is much more complex (and interesting) than" a singular focus on "information intentionally transmitted by speakers and writers" allows for (p.3). Gregoromichelaki et al. (2011) propose in the context of the broader Dynamic Syntax program that utterance processing is more readily explained with reference to the "incremental and monotonic growth of semantic representations", and on the basis of their modelling of so-called split utterances conclude that "recognition of the context of speaker intentions is not a necessary condition of human interaction" (p.200). ${ }^{7}$ And Gibbs (in press) argues with reference to psycholinguistic experiments of the production and processing of verbal irony that "people's ironic behaviors result from their self-organizing tendencies even before any intention to speak or write in certain ways ever reaches awareness" (Gibbs in press: 11). In other words, psychological research indicates that not all forms of irony are necessarily deliberate or even intentional. Such work also indicates significant movements towards an account of cognition in interaction, as called for by Levinson (2006a, 2006b), among others. And while Wedgwood (2011) appears to assume that any "cognitive" account of communicative phenomena would necessarily assume "local" intentions to be central, this assumption appears increasingly unwarranted in light of various lines of research in cognitive pragmatics. It thus seems high time that an approach to theorising cognition which addresses the requirements that our understandings of interaction impose - cognition for interaction - be further developed. In this way, we can move away from the unnecessary constraints on the analysis of communicative interaction that an attempt to boil down all interaction to "local" intentions entails.

In the following section, I deal in more detail with Wedgwood's (2011: 523) claim that an "interactional" analysis necessarily appeals to "intention-based reasoning", as it is the validity (or not) of this charge which is ultimately the most telling as to the relative value of an "interactional" account of communication. I argue that such a charge is not only groundless, but also analytically unproductive.

\section{On "locating" intentions in communicative interaction}

In recent work I have discussed problems that arise when attempting to locate Gricean or communicative intentions in actual interactional data (Haugh 2008c, 2009).

Wedgwood (2011: 535-537) revisits one of my examples and argues for the necessity of an individual-, utterance-, and intention-based account of this interaction. It is difficult to untangle Wedgwood's analysis from my own, as he completely misses my 
argument that an individual- and utterance-based analysis is necessary but not sufficient to fully account for interaction. In order to contextualise Wedgwood's arguments, then, I will (1) briefly outline the two key claims I was trying to make with reference to this particular example in my earlier papers (Haugh 2008c: 62-64, 2009: 103-104), and then (2) outline the approach to the "participant's viewpoint" that was presumed in my analysis in order to counter Wedgwood's caricature of it. I will next (3) unpack my analysis of this example, since it was necessarily compressed in the context of those two papers, in order to illustrate the close analysis of the data at hand which was involved. I will then (4) contrast this with the speculative interpretations Wedgwood offers, which arise as a consequence of his singular focus on framing utterance interpretation relative to putative "local" intentions. I conclude (5) by suggesting that the sociocognitive processes we propose must be properly responsive to the demands of interaction, and reiterate why monadic processes are necessary but not sufficient in an account of cognition for interaction.

The excerpt which was revisited in Wedgwood's (2011) recent critique is reproduced below. I have included the original turn numbering on the right hand side since this excerpt is taken from the middle of a longer fifteen minute recording of a conversation between Emma and Chris who were meeting for the first time. The questions I raised about locating putative communicative intentions were specifically in relation to the interpretation of Chris's utterance in turn 11.

(2) ERCH: 8:18-8:39

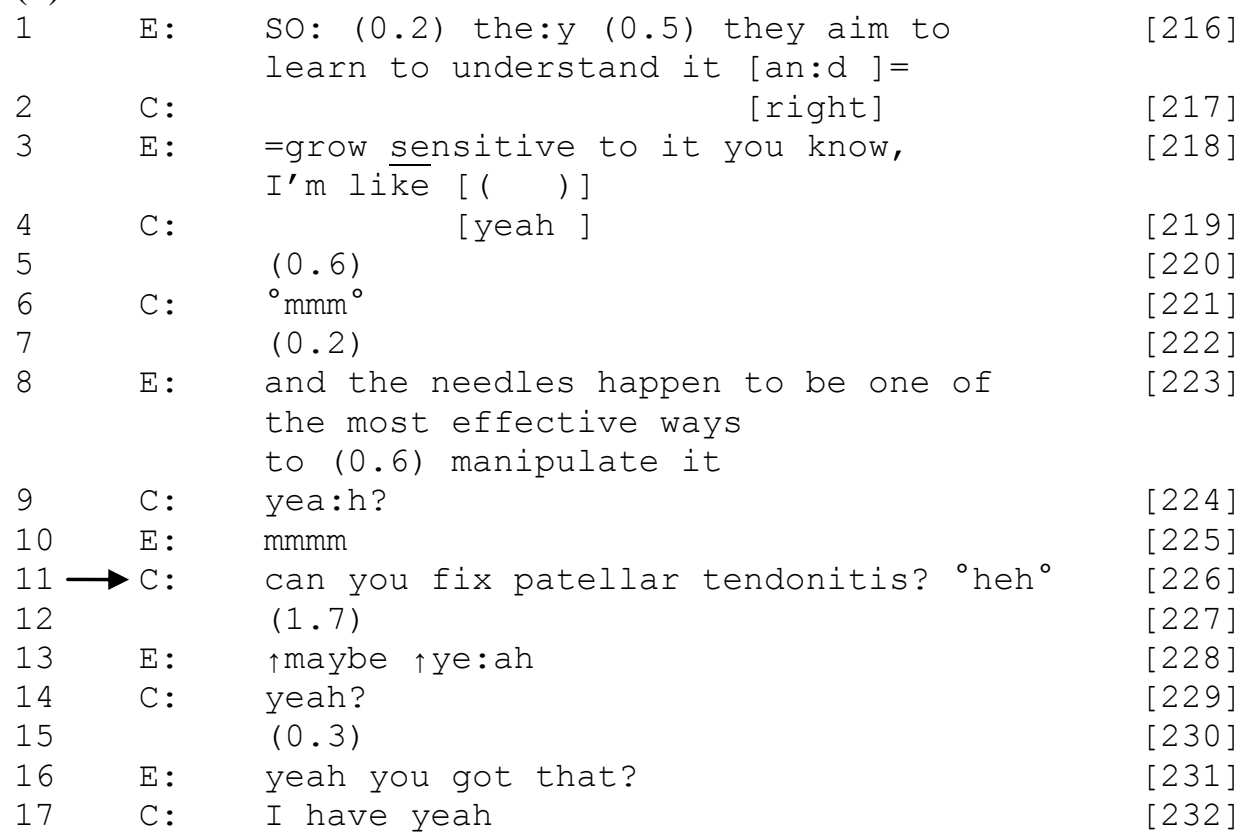

I noted that following this excerpt Emma made an offer of treatment that was (tentatively) accepted by Chris (Haugh 2008c: 63, 2009: 104), and thus Chris's utterance was evidently treated as request implicative. The question facing the analyst is how did Emma and Chris reach this understanding?

(1) In Haugh (2008c), my key claim was that "speculation about the intentions of Chris, or what Emma interpreted as Chris' intentions is analytically unproductive in regards to determining what was implied" (p.64, emphasis added). I pointed out that Emma could not have been sure whether Chris had an a priori intention to raise the possibility of seeking treatment, or to teasingly challenge her, or even both, and we (i.e. the analysts) do not know for sure what interpretations of Chris's utterance in 
turn 11 that Emma might have entertained. What we do know is that Emma displayed an interpretation of Chris's utterance as request implicative in her subsequent responses, and that Chris accepted this understanding in his subsequent responses.

In Haugh (2009), my key claim was that the "the inferencing underlying this implicature is necessarily interdependent", by which I meant that "Chris's and Emma's inferences about what is meant by Chris's question in line 11 are dependent on the other's displays of the inferences they have made" (p.104). It thus follows, I argued, that we cannot simply talk about inferences made about putative speaker intentions in interpreting utterances in isolation. Utterance interpretation occurs in sequentially organised discourse, and thus Chris and Emma's inferential work about Chris's utterance in turn 11 is necessarily dependent on their inferences about each other's inferences. In other words, inferences about (speaker) meanings are always reflexive and contingent on the understandings by self and other displayed in prior and subsequent turns. This is what is meant, at least in part, by dyadic as opposed to monadic cognition (Arundale and Good 2002).

(2) In order to contextualise my analysis and expand upon it, it is worth first outlining the key principles upon which it builds, namely, those of ethnomethodology and conversation analysis (Heritage 1984; Schegloff 2007). The primary one is that communicative interaction is fundamentally organised as a "vehicle of human action" (Schegloff 1991), and thus any analysis of meaning in interaction must necessarily be contextualised relative to social actions. I would not go as far as some to claim that the analysis of social actions is more important than meaning in conversational interaction, as any analysis of social action, in my view, necessarily presumes an analysis of the content of social actions, or what they are about (i.e. a request to $x$, an invitation to $x$ and so on). Instead, I would simply suggest that meanings in communicative interaction always arise in the context of sequentially achieved social actions. Another key principle is that intersubjectivity in conversational interaction is locally managed and locally adapted (Schegloff 1992: 1138). This does not preclude abstraction away from localised interactions in theorising meaning, but it does mean any theorisation must be responsive to the temporality and sequentiality that underpins the cognitive-interactional mechanisms underlying meaning. It has also been demonstrated that that actions and meanings are implemented on a "turn-by-turn basis", and "by means of this organization, a context of publicly displayed and continuously up-dated intersubjective understandings is systematically sustained" (Heritage 1984: 259, original emphasis). In other words, next turns provide evidence of the understandings of recipients of prior turns. However, it is important to note that such understandings are "indirectly exhibited in their own turns", which means "a second speaker's analysis of a prior is presented indirectly and must be inferred" by others (Heritage 1984: 260). An analyst must therefore focus on evidence of participant's understanding displayed in current as well as in prior and next turns. It is also important to note that next turns do not necessarily display straightforward understandings of prior turns. Heritage (1984) cautions that

the 'official' treatments of talk occurring at the conversational surface are the starting point for interpretative and analytic work and cannot be treated simply as unproblematic representations of what the speakers' understandings or intentions in the talk consisted of (p.260, emphasis added).

In the case of analysing implicatures or implicated actions it is thus particularly important to draw on other sources of analytical evidence as well. This closely relates 
to yet another principle, namely, that participants may be "pursuing 'possible understandings' of turns at talk - including their owns at talk - along multiple lines, and are thereby prepared to recognize even ones arrived at by others that might have been thought elusive" (Schegloff 2006: 147, emphasis added). In other words, interpretations of utterances are initially always provisional as they are inevitably contingent on what follows. The final principle is that analyses should grounded in prior research that demonstrates interactional practices that are found to be recurrent in situated discourse (including within the interaction in question) in order to attest to the relative plausibility of the 'possible understandings' that are proposed. In other words, a putative understanding can be justified with reference to prior studies that illustrate recognisable (to the participants) ways of accomplishing such understandings. ${ }^{8}$ I might add that this approach to the analysis of the "participant's perspective" is much more closely tied to the content and form of individual utterances (as well as how they are related in interactional sequences) than Wedgwood's speculation about the possible intentions of Chris, despite his claims to the contrary (cf. Wedgwood 2011: 536).

(3) I now turn to the question of what justifies the analysis of Chris's utterance as either a possible challenging tease or as request implicative, which is what leads to analytical equivocality about his putative or alleged intentions. It is important to start this analysis by noting that Chris's utterance in turn 11 is in the basic form of a polarinterrogative ("can you fix patellar tendonitis"), and is oriented to as an informationseeking question by Emma in her response in turn 13 ("maybe yeah"). In the first possible space to respond to Chris's utterance, then, Emma orients to his utterance at the level of what is said. Chris then seeks confirmation of the veracity of the information in turn 14 with a truncated polar-interrogative ("yeah?"), to which Emma reconfirms, in turn 16, her prior response in turn 13. She appends in the same turn a new turn-construction unit, which involves yet another polar-interrogative ("you got that?"). Chris then confirms that he does have the condition in question in turn 17.

Emma's polar-interrogative in turn 16 thus constitutes evidence that she has oriented to Chris's utterance in turn 11 as possibly request implicative (i.e. that Chris would like to seek acupuncture treatment from her). In the minute or so of discourse that follows (data not shown) Emma goes on to ask Chris questions about his condition before leading into a tentative offer of treatment (turns 288, 291), which is subsequently tentatively accepted by Chris (turn 298), as evident in the excerpt below.

(3) ERCH: 9:40-9:56

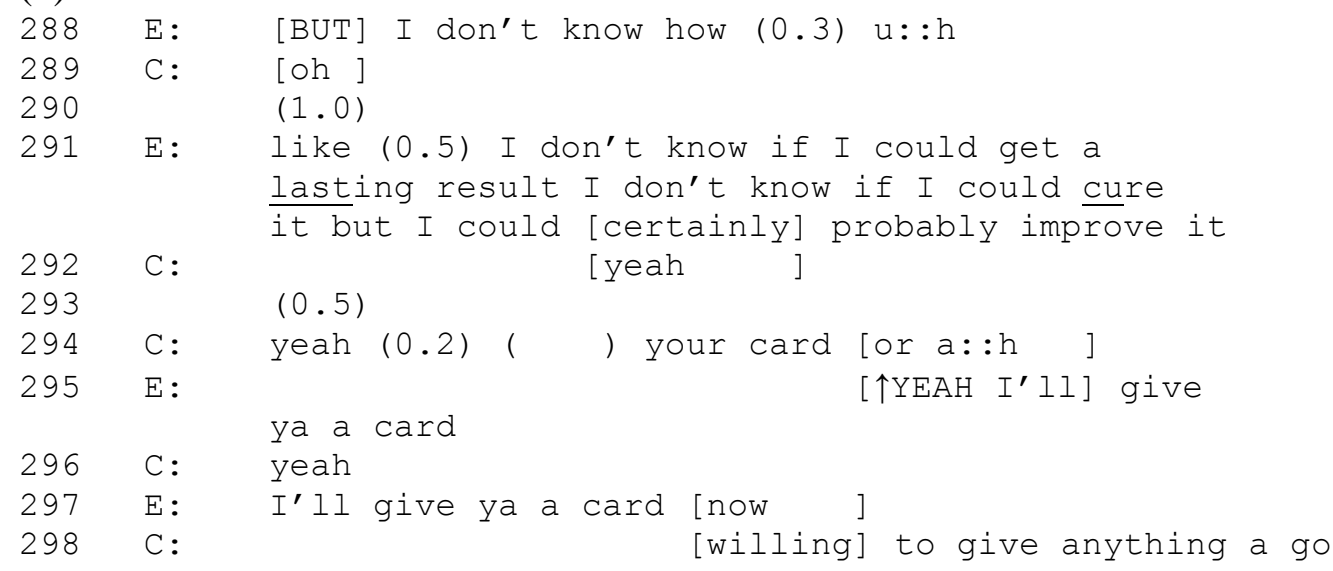

It is evident from previous studies of the sequential development of requests in English (Curl and Drew 2008; Heinemann 2006; Schegloff 2007: 62, 90; Stevanovic 
2011) that Chris's utterance would be recognisable to the participants as a possible pre-request in that it involves an information-seeking question that could be understood as "gaug[ing] the likelihood of a possible request being granted before it is performed" (Liddicoat 2007: 132). That it is recognised as pre-request implicative is evident from Emma's subsequent offer of treatment for Chris's condition.

While at first glance a consideration of the sequential development of this "question-answer" sequence in turns 11-17 (or turns 226-232 in the full transcript), and the subsequent offer in turns 288-298 might seem irrelevant to the analysis of Chris's utterance in turn 11 as request-implicative, it is in fact critical. This is because although one might assume that the preferred (in the CA sense of normative) response would be a go-ahead response leading into a request by Chris, Schegloff (2007) points out that the "the preferred response to the pre-request is to pre-empt the need for a request altogether by offering that which is to be requested" (p.90, emphasis added). And this is indeed exactly what happens in this interaction. Emma pre-empts the need for Chris to make his request explicit through an offer that is followed by a line of pre-consultation type questioning where Emma assesses whether she is able to offer treatment for Chris's condition. This is important to note because it undermines Wedgwood's (2011) first “alternative" reading of Chris's utterance, namely, that "Chris's attempt to communicate in line 11 is initially just not very successful" (p.536). In fact, the two participants develop an understanding of Chris's utterance in turn 11 as request implicative consistent with normative or preferred ways of responding to recognisable pre-requests, namely, with pre-emptive offers, as found in extensive empirical analyses of requests in situated, naturally occurring discourse. I might add that labelling an utterance as "successfully" or "unsuccessfully" communicating something constitutes Wedgwood's evaluation of that excerpt, but this evaluation is not evidenced with reference to the data at hand, and thus does not amount to empirical analysis.

The analysis of Chris's utterance in turn 11 as implicative of a possible challenging tease (i.e. something like "but could you treat something like this?") can also be also tied to the interactional data at hand. The first thing to note in examining the plausibility of this "possible understanding" of the utterance as implying a teasing challenge is the design of the turn and what precedes it. The utterance itself is delivered with "compressed" intonation, apart from the utterance-final rising intonation, which is consistent with studies of the intonation of mockery (Attardo et al 2003; Keltner et al 2001: 324). A laughter particle is also appended ("heh") immediately following the polar-interrogative. On its own the interpretation of the laughter particle is of course equivocal, but it is important to note that utterance-final laughter particles have been demonstrated to orient the recipient to the possibility of joining in to laugh about a possible mocking remark (Glenn 2003; Jefferson 1979; Schenkein 1972). In other words, through the laughter particle, the possibility of a non-serious or jocular interpretation of Chris's utterance (i.e. as a tease) is a possible understanding. The possible understanding of the utterance as implicating a teasing challenge arises from the content of the interrogative itself, embedded within which there is a particular candidate answer (Pomerantz 1988), namely, that Emma can, or perhaps cannot, treat patellar tendonitis. The plausibility of the analysis of this utterance as implying a possible teasing challenge is further evidenced in the fact that Emma has been extolling the advantages of acupuncture to Chris. Some of this was shown in the excerpt I analysed, although Emma had in fact been talking about acupuncture for most of their conversation. As Drew (1987) points out in a study of teasing and tease responses in English, mockery may be locally occasioned in 
response to the target "overdoing" or exaggerating a particular action, in this case, extolling the virtues of acupuncture. Indeed, we can find an example of Emma and Chris recognisably achieving a jocular tease in response to Emma extolling the virtues of her acupuncture teacher later in that same conversation (Haugh 2010a: 2113-2114). The strongest evidence, however, that a teasing challenge is potentially implied here by Chris is an exchange between them that occurs just over a minute prior to that excerpt, which is reproduced below.

(4) ERCH: 7:03-7:15

\begin{tabular}{|c|c|}
\hline 181 & $\begin{array}{l}\text { so what's the basic idea behind acupuncture? } \\
\text { I mean [I know a little about] it but, [you know] }\end{array}$ \\
\hline $\begin{array}{l}182 \\
183\end{array}$ & $\left.\begin{array}{lllll} & {[\mathrm{OH}} & \mathrm{COME} & \mathrm{ON} & \mathrm{HEH}\end{array}\right] \quad\left[\begin{array}{lll}. \text { Hhhh } & \end{array}\right.$ \\
\hline 184 & I mean \\
\hline 85 & $(0.4)$ \\
\hline 186 & $\mathrm{u}:: \mathrm{m}=$ \\
\hline 187 & does it wo (hh)rk? kheh \\
\hline 188 & ye:ah it works= \\
\hline 189 & ye $(\mathrm{hh}) \mathrm{h} ?$ \\
\hline 190 & $\begin{array}{l}\text { yeah yeah it really works (0.3) there's no } \\
\text { (.) no question about it working (0.5) but } \\
\text { nobody knows exactly what the mechanism is (0.5) } \\
\text { scientifically }\end{array}$ \\
\hline
\end{tabular}

Here we see that Emma orients to Chris's question in turn 181 as implying he is sceptical or doubtful about the effectiveness of acupuncture by responding in turn with a display of possible exasperation ("oh com on") delivered in a markedly louder voice with laughter (turn 182). Chris's implied challenge is subsequently made more explicit when he asks whether it works (turn 187). The occurrence of laughter particles, including the utterance-final "heh" here orients Emma to the possibility of joining in to laugh about the question, thereby framing it as non-serious or teasing in nature. Emma asserts, in response, that it does work (turn 188), and reconfirms this in turn 190, in response to Chris seeking further confirmation (turn 189). The fact that Chris seeks further confirmation is once again implicative of his possible scepticism. Emma then moves into an explanation of how acupuncture works in "non-scientific" terms (turn 190), which continues on until Chris's question about patellar tendonitis in turn 11 (or turn 226 in the complete transcript).

It is important, then, to note that through this Chris and Emma have established Chris's possible scepticism about the efficacy of acupuncture, which is particularly salient in that this is the first time they have met. They have also jointly accomplished a non-serious or jocular frame in orienting to the issue of the efficacy (or not) of acupuncture. Also quite striking is the similarity in utterance design between Chris's prior utterance in turn 187 (“does it work? heh") which is demonstrably oriented to by both as a tease, and his subsequent utterance in turn 226 ("can you fix patellar tendonitis? heh"). Interpreting Chris's utterance in turn 11 (orr turn 226 in the full transcript) as implicative of a teasing challenge is thus indeed a possible understanding at play here, as evidenced by close examination of the design of the turn itself, as well as what precedes it, in conjunction with prior studies of recognisable practices of teasing in English.

The fact that Emma does not orient to this possible understanding (or provisional interpreting) in subsequent turns means that this understanding remains simply that: a possible understanding that is not interactionally foregrounded. As I previously argued, what is conjointly co-constituted by Emma and Chris is an 
understanding of Chris's utterance as information-seeking as well as request implicative. But this does not preclude the possibility of other understandings. It would be a mistake for us, as analysts, to ignore evidence from studies of interaction that point to the emergence of multiple understandings of meaning and action amongst participants at times, some of which may be interactionally foregrounded and some of which may not. It is the contingency of such understandings, and the ways in which they can be foregrounded or backgrounded, which underpins the inherently dynamic nature of meaning in interaction.

(4) Having carefully unpacked my prior analysis, I now turn to the other "readings" of Chris's utterance that Wedgwood (2011) offers. He first claims that "it is possible...that Chris actually intends to project indeterminacy or vagueness through his line 11 utterance" (p.536). There is very little evidence to support this reading because Emma and Chris jointly accomplish an understanding of his utterance as a pre-request implicative in a manner consistent with a normative practice of preempting request with an offer (Schegloff 2007: 90). Attributing the "design" and sequential placement of this utterance to simply issues of "politeness/face-saving" thus constitutes a very superficial analysis indeed. That is not to say that such issues do not arise, but they need to be examined in conjunction with a fully developed analysis of the interactional achievement of meanings and actions in this interaction, not as a substitute for close analysis. The second reading that Wedgwood offers is that Chris is "deliberately changing the subject" (fn.4, p.540) through this utterance. It is difficult to understand on what grounds Wedgwood considers this a "change of subject", since this question still remains broadly focused on the efficacy of acupuncture. There is, in any case, nothing to indicate in the design or sequential placement of this question to suggest that we are dealing with "topic shift", as any cursory examination of the literature would suggest (Jefferson 1993; Schegloff 1990, 2007: 169-180). To put it simply, there is no evidence in the data at hand that we are dealing with a "change of subject". Thus, while Wedgwood (2011) argues there are other equally plausible interpretations of Chris's utterance in turn 11, and assumes that my analysis is simply an "intuitive reading" of the interaction (p.536), I would counter that the interpretations that Wedgwood offers are speculative and not justified by the data at hand, and that his appeal to intentions forces him to engage in the "intuitive reading" that he protests against. The fact that Wedgwood fails to identify with any certainty Chris's "local" intention, despite that fact that Emma and Chris evidently do understand each other, and that his attempts to do so lead him to make unsubstantiated claims about the utterance being "unsuccessful", or an indication of Chris having a "vague" intention, or even an attempt to "change the subject", affirms my point that speculation about a priori intentions is analytically unproductive. Rather than speculating about the putative intentions of speakers, then, it is much more productive, I would contend, to carefully examine the design and content of utterances themselves, as well as the responses of participants, and thus ground the analyst's interpretations of possible understandings of participants through close examination of the interactional data at hand, in conjunction with careful reading of prior studies in the literature that deal with similar phenomena. ${ }^{9}$

(5) Finally, I turn to the issue of the implications of this analysis for how we might frame the possible sociocognitive processes at play here. ${ }^{10}$ The first thing to note is that we are potentially dealing with a possible higher-order intention here, namely, Chris's possible desire to seek treatment for his condition. However, this higher-order intention cannot be pinned down anywhere in this particular conversation, never mind to his utterance in turn 11 . Thus "locating" a higher-order 
intention here proves no easier than locating a communicative intention. There is one important difference, however, when considering the two. This arises from the fact that Chris's utterance in turn 11 (or turn 226 in the full transcript) marks a possible beginning to a different participation framework (Goffman 1981) in this conversational interaction. Up until that point in the conversation, Chris and Emma have been engaging in the activity of what might be loosely termed "getting acquainted" (Haugh 2011; Maynard and Zimmerman 1984; Svennevig 1999). In such conversations, specific interactional "goals" are less evident, or at least are rather broad in nature relating to the desire to "get on" with someone or establish a "good start" to a relationship and so on. Chris's utterance, however, proffers a different kind of participation framework, namely, a consultation about his condition with a professional working in "alternative" medicine. Part of the new interpretative frame that this participation framework engenders is an understanding that a "patient" (here ostensibly Chris) normally has a "goal", namely, to receive treatment. The question is how do they achieve intersubjectivity in regards to this broad interpretative frame? To put it in other terms, how is that they reach an understanding that they are jointly engaged in a "medical consultation" rather than (just) "getting acquainted"? In a broadly Gricean framework one might argue that it is through Emma recognising Chris's communicative intention behind his utterance in turn 11, that she attributes a higher-order intention (to possibly seek treatment), which in turn leads them to weintend the activity of "consulting". But this does not explain how in the course of this specific point in the interaction they could jointly reach such understandings.

Wedgwood (2011) provides no analysis of this issue as a result of his singular focus on "local" intentions, but it is an important puzzle that any account of the cognitive processes underlying (and perhaps sometimes driving) conversational interaction must solve.

I would suggest that any attempt to solve the puzzle of how such intersubjectivity is accomplished needs to start by appreciating that any such account must be responsive to the interdependent nature of the inferential work underpinning this sequence (cf. Haugh 2009). This analysis of the way in which inferences about this utterance become interdependent draws from Arundale's (2010) distinction between provisional and operative interpretings. A provisional interpreting of an utterance is an understanding on the part of one participant that is "not yet assessed in view of uptake" by the other participant (or participants) (p.2080). In other words, the recipient(s) have not yet displayed evidence of their understanding of the utterance in a subsequent turn. This does not mean that a participant is necessarily uncertain about his or her understanding, but simply that it has not been grounded with reference to the responses of others to that utterance. An operative interpreting of an utterance is an understanding of one participant that has been "assessed in view of uptake" by other participants (p.2080), although this does not mean that a participant cannot subsequently change his or her understanding in light of further interaction. Both provisional and operative interpretings are necessarily contingent; the distinction rests on whether or not they are grounded in subsequent uptake by another participant or participants. In order to make the discussion of this complex issue tractable I will offer a simplified version of a short portion of the excerpt starting with Chris's utterance in turn 11.

(5)

Chris's utterance a: can you fix patellar tendonitis?

Emma's utterance b: maybe yeah 
Chris's utterance c: yeah?

Emma's utterance d: yeah you got that?

Chris's utterance e: I have yeah

Some of the main inferences that arise here if we take it as given that an operative interpreting of utterance $a$ as pre-request implicative is displayed by Emma through utterance $d$, and by Chris through utterance $c$, can be outlined as follows:

C1: Chris's inference of Emma's projected interpreting of his utterance a.

E1: Emma's inference of Chris's provisional interpreting of his utterance a.

C2: Chris's inference of Emma's provisional interpreting of his utterance $a$ in light of her utterance $b$.

E2: Emma's inference of Chris's operative interpreting of his utterance $a$ in light of his utterance $c$.

C3: Chris's inference of Emma's operative interpreting of his utterance $a$ in light of her utterance $d$.

What can be seen here is that Chris's inference about Emma's operative interpreting of utterance a (C3) is dependent on Emma's display of her inference about Chris's operative interpreting of utterance a (E2), as well his inference about Emma's provisional interpreting of utterance a $(\mathrm{C} 2)$, which is dependent, in turn, on Emma's display of her inference about Chris's provisional interpreting of utterance $a$ (E1), and Chris's initial inference about Emma's projected interpreting of utterance a $(\mathrm{C} 1)$. It follows that Chris's final inference at this point in the sequence $(\mathrm{C} 3)$ is afforded and constrained by his own prior inferences $(\mathrm{C} 2, \mathrm{C} 1)$, as well as inferences made evident by Emma (E2, E1), which are in turn, afforded and constrained by inferences that Chris has made evident (C2). This means that Chris's inference about Emma's operative interpreting of utterance $a$ is interdependent as it is afforded and constrained by Emma's inferences, which are in turn afforded and constrained by Chris's inferences. It is important to note that this cognitive interdependence is achieved across turns at talk not at any one single turn. It is thus of a different order of reflexivity than that involved in attributing communicative intentions. It is for this reason that conversational interaction requires consideration not only of monadic, independent cognitive processes (e.g. those leading to $\mathrm{C} 1$ ), but also dyadic, interdependent cognitive processes (e.g. those leading to C3). It is only with reference to the latter, interdependent cognitive processes, as well as traditional monadic cognitive processes, that we can hope to explain how Emma and Chris reach an understanding that they have shifted from an interpretative frame of getting acquainted into a pre-medical consultation.

The point that Wedgwood seems to fail to appreciate is that my analysis, which draws in part from research and methods in conversation analysis, but which is ultimately broadly contextualised within the Conjoint Co-Constituting Model of communication (Arundale 1999, 2010), is in reality rather cognitive in focus. Wedgwood's (2011) assertion that "interactional" approaches neglect the cognitive dimension of communication perhaps rests on the assumption that any discussion of cognition that is not framed with reference to "local" or communicative intentions (i.e. on his terms) is by definition not cognitive in focus. But one wonders what provisional and operative interpretings, inferences, expectations, beliefs and the like are if not cognitive? The point I have tried to make here is that while individuals are obviously cognitively autonomous, cognitive processes themselves may either remain 
independent or become interdependent. It is the latter which has been neglected in accounts of communicative interaction that attempt to reduce everything to communicative or "local" intentions.

\section{Concluding remarks: towards a cognition for interaction}

I would like to conclude this response, having disagreed with almost every claim made by Wedgwood (2011), by highlighting at least one point on which I think we do agree. He suggests early in his paper that

interactional and emergent phenomena necessarily involve the interaction of something and emergence from something, and that proper explanation of such phenomena should elucidate, where possible, the relationship between the emergent phenomena and the nature of individual contributions to the interactions that produce them (p.518, original emphasis).

I could not agree more (despite Wedgwood's claim to the contrary), although we appear to disagree on how to accomplish this. There is clearly very fruitful work that can be done in collaborations between more cognitively and more interactionally focused researchers in pragmatics. And indeed there are a number of approaches being developed that focus on doing just that. The sociocognitive model being developed by Kecskes (2010) is one example. The incremental model of utterance processing being developed by Gregoromichelaki et al (2011) is another. And, of course, the Conjoint Co-Constituting Model of communication is yet another (Arundale 1999, 2010; Arundale and Good 2002). All of these models have one thing in common, namely, they are responsive (to varying degrees) to requirements that interaction places on cognition. They differ in their understandings of intention, and in their relative commitment (or not) to making recourse to intention attribution in accounts of meaning in interaction (Arundale 2008, this issue; Levinson 2006a, 2006b). Clearly much more work remains to be done to address the complex issues raised here, including the place of intentions and intentionality in an account of cognition for interaction.

My contention is that there are multiple methodological perspectives we can draw from in further developing such an account, ranging from philosophical considerations of intention to the analysis of interactional data, through to experimental work employing techniques inherited from neuroscience. Of course, we should be wary that methodological eclectism does not unwittingly generate theoretical or analytical incoherence. And indeed, reiterating what I wrote in my introduction to the special issue of Intercultural Pragmatics on intention, we must also necessarily discard certain views and develop new alternatives in the course of this endeavour (Haugh 2008a: 107). However, this process of discarding certain views and developing new alternatives should be grounded in an appreciation of the different understandings of intention that exist in pragmatics, as well as a healthy respect for the methodological commitments of different approaches to the analysis of pragmatic phenomena. In that way dialogue across disciplines can be fruitful rather than divisive. The questions I raised in relation to the role of communicative intentions in the analysis of conversational interaction were intended as a way of opening up dialogue. A rebuttal such as Wedgwood's that attempts to shut down such discussions is, in my view, counterproductive to say the least. As I previously concluded: 
disciplines do not advance by avoiding the slippery questions that lay at their very foundations. It is in dealing with seemingly intractable issues that we can see with greater clarity through to the epistemological, ontological, and methodological assumptions underlying different research traditions in pragmatics (Haugh 2008a: 107).

It is in that spirit I offer this response to Wedgwood's (2011) attempted critique and to those who are interested in the complex issues that it raises.

\section{Acknowledgments}

I would like to thank Robert Arundale for his very helpful comments and suggestions, as well as Istvan Kecskes for offering me the opportunity to write this response. Any errors or fallacies in this paper, however, are entirely my own.

\section{Notes}

1. The overview of intention and intentionality in this section is necessarily compressed. For a more indepth overview see Bara $(2010,2011)$ or Haugh and Jaszczolt (2012).

2. It has been pointed out that Grice's formulation of communicative intention actually involved two degrees of reflexivity, as the second-order intention (that the first-order intention to inform or represent be recognised by the hearer) was further embedded within a third-order intention (i.e. to intend that the hearer's recognition of the first-order intention be the reason for the hearer recognising the speaker's secondorder intention), although the utility of this third-order intention has been disputed (Bara 2010: 82-83; Searle 2007: 14). For the sake of exposition, I will only make reference to the simpler second-order communicative intention, which is preferred by Relevance theorists, for instance.

3. Consistent with this general assumption, Wedgwood (2011) characterises intentions as "'what the speaker wants to get across' through a particular utterance, at the point at which it is formulated" (p. 526, emphasis added).

4. By cooperative it is not meant "agreeable" or the like, but simply that no individual can accomplish the activity in question on his or her own.

5. See Haugh and Jaszczolt (2012: 106-108) for a brief overview of this fascinating new line of research on the cognitive states-processes underlying communication.

6. This is not to suggest that the definition and theorisation of impoliteness is in any way settled (see Bousfield 2010 for a spirited defence of an intention-based model of impoliteness), but only to point out that coherent accounts of socioculturalinteractional" features of dialogue need not necessarily treat intention recognition as ineliminable contra Wedgwood (2011: 537). 
7. Interestingly, Haugh's (2010b) analysis of the interactional achievement of coconstructions indicates that first speakers (i.e. those who initiate the co-construction) hold themselves committed to and thus primarily accountable for those co-constructed utterances as opposed to the interlocutor who "finishes" the utterance. This could be taken as evidence of an orientation to the first speaker's intentions (in the folk, discursive sense), but as previously discussed, this does not constitute evidence that interlocutors are necessarily inferring the speaker's communicative intentions (Gregoromichelaki et al 2011). What this does illustrate is the utility of allowing for multiple understandings of intention.

8. Wedgwood's (2011) "critique" of the bias towards the "analyst's omniscient perspective" (p.533) in my analysis thus fails to recognise that there are alternative ways in which to conceptualise and analyse the "participant's perspective" in empirically grounded ways.

9. Wedgwood (2011) allows for only one understanding of the "participant's viewpoint", namely, the "internal states of the individual" (p.534) in terms of presumed "mechanisms of communication" (p.533). He thus fails to appreciate the very different approach to conceptualising the participant's viewpoint in CA, where the analyst's interpretation is grounded in evidence participants provide to one another of their interpretations of the interactional import of utterances (among other things).

10. See Haugh (2012: 261-266) for another account of emergence in interaction and its implications for traditional accounts of the cognitive processes assumed to underlie communicative interaction.

\section{References}

Airenti, Gabriella, Bara, Bruno, and Colombetti, Marco. 1993. Failures, exploitations and deceits in communication. Journal of Pragmatics 20. 303-326.

Arundale, Robert. 1999. An alternative model and ideology of communication for an alternative to politeness theory. Pragmatics 9(1). 119-154.

Arundale, Robert, \& David Good. 2002. Boundaries and sequences in studying conversation. In Anita Fetzer \& Christine Meierkord (eds.), Rethinking Sequentiality. Linguistics Meets Conversational Interaction, 121-150. Amsterdam: John Benjamins.

Arundale, Robert. 2008. Against (Gricean) intentions at the heart of human interaction. Intercultural Pragmatics 5(2): 231-260.

Arundale, Robert. 2010. Constituting face in conversation: face, facework and interactional achievement. Journal of Pragmatics 42(8). 2078-2105.

Arundale, Robert. this issue. On understandings of communication: a response to Wedgwood. Intercultural Pragmatics 9(2).

Attardo, Salvatore, Jodi Eisterhold, Jennifer Hay, \& Isabella Poggi. 2003. Multimodal markers of irony and sarcasm. Humor 16(2). 243-260.

Austin, J. L. 1962. How to Do Things with Words. Oxford: Clarendon Press.

Bara, Bruno. 2011. Cognitive pragmatics: the mental processes of communication. Intercultural Pragmatics 8(3). 443-485.

Bara, Bruno. 2010. Cognitive Pragmatics. Cambridge, MA: MIT Press. 
Bargh, John, \& Erin Williams. 2006. The automaticity of social life. Current Directions in Psychological Science 15(1). 1-4.

Becchio, Cristina, \& Cesare Bertone. 2004. Wittgenstein running: neural mechanisms of collective intentionality and we-mode. Consciousness and Cognition 13. 123-133.

Bousfield, Derek. 2010. Researching impoliteness and rudeness: issues and definitions. In Miriam A Locher and Sage L Graham (eds.), Interpersonal Pragmatics, 101-134. Berlin: Mouton de Gruyter.

Brandom, Robert. 1994. Making it Explicit. Reasoning, Representing and Discursive Commitment. Cambridge, MA: Harvard University Press.

Bratman, Michael. 1999. Intention, Plans, and Practical Reason. Stanford, CA: CSLI Publications.

Breheny, Richard, Napoleon Katsos, \& John Williams. 2006. Are generalised scalar implicatures generated by default? An on-line investigation into the role of context in generating pragmatic inferences. Cognition 100. 434-463.

Chevallier, Coralie, Ira, Noveck, Tatjana Nazir, Lewis Bott, Valentina Lanzetti, \& Dan Sperber. 2008. Making disjunctions exclusive. The Quarterly Journal of Experimental Psychology 61. 1741-1760.

Ciaramidaro, Angela, Mauro Adenzato, Ivan Enrici, Susanne Erk, Lorenzo Pia, Bruno Bara, \& Henrik Walter. 2007. The intentional network: how the brain reads varieties of intentions. Neuropsycholgia 45. 3105-3113.

Clark, Herbert 1996. Using Language. Cambridge: Cambridge University Press.

Culpeper, Jonathan. 2005. Impoliteness and entertainment in the television quiz show: the weakest link. Journal of Politeness Research 1(1). 35-72.

Culpeper, Jonathan. 2011. Impoliteness: Using Language to Cause Offence. Cambridge: Cambridge University Press.

Curl, Traci, \& Paul Drew. 2008. Contingency and action: a comparison of two forms of requesting. Research on Language and Social Interaction 41(2). 129-153.

Drew, Paul. 1987. Po-faced receipts of teases. Linguistics 25. 219-253.

Edwards, Derek. 2008. Intentionality and mens rea in police interrogations: the production of actions as crimes. Intercultural Pragmatics 5(2). 177-199.

Evans, Jonathan St. 2008. Dual-processing accounts of reasoning, judgment, and social cognition. Annual Review of Psychology 59. 255-278.

Garfinkel, Harold. 1967. Studies in Ethnomethodology. Englewood Cliffs, NJ: Prentice-Hall.

Garmendia, Joana. 2011. She's (not) a fine friend: "saying" and criticism in irony. Intercultural Pragmatics 8(1). 41-65.

Garrett, Merrill, \& Robert Harnish. 2007. Experimental pragmatics. Testing for implicitures. Pragmatics and Cognition 15(1). 65-90.

Garrett, Merrill, and Harnish, Robert. 2009. Q-phenomena, I-phenomena and impliciture: some experimental pragmatics. International Review of Pragmatics 1(1). 84-117.

Geurts, Bart. 2010. Quantity Implicatures. Cambridge: Cambridge University Press.

Gibbs, Raymond Jr. 1999. Intentions in the Experience of Meaning. Cambridge: Cambridge University Press.

Gibbs, Raymond Jr. in press. Are ironic acts deliberate? Journal of Pragmatics.

Gil, José Maria. 2011. Relevance theory and the unintended transmission of information. Intercultural Pragmatics 8(1). 1-40.

Gilbert, Margaret. 2009. Shared intention and personal intentions. Philosophical Studies 114. 167-187. 
Glenn, Phillip. 2003. Laughter in Interaction. Cambridge: Cambridge University Press.

Goffman, Erving. 1981. Forms of Talk. Philadelphia: University of Pennsylvania Press.

Gregoromichelaki, Eleni, Ruth Kempson, Matthew Purver, Gregory Mills, Ronnie Cann, Wilfried Meyer-Viol, \& Patrick Healey. 2011. Incrementality and intention-recognition in utterance processing. Dialogue and Discourse 2(1). 199-233.

Grice, H. Paul. 1957. Meaning. Philosophical Review 66(3). 377-388.

Haugh, Michael. 2008a. Intention in pragmatics. Intercultural Pragmatics 5(2). 99110.

Haugh, Michael. 2008b. Intention and diverging interpretings of implicature in the "uncovered meat" sermon. Intercultural Pragmatics 5(2). 201-229.

Haugh, Michael. 2008c. The place of intention in the interactional achievement of implicature. In Istvan Kecskes \& Jacob Mey (eds.), Intention, Common Ground and the Egocentric Speaker-Hearer, 45-86. Berlin: Mouton de Gruyter.

Haugh, Michael. 2009. Intention(ality) and the conceptualisation of communication in pragmatics. Australian Journal of Linguistics 29(1). 91-113.

Haugh, Michael. 2010a. Jocular mockery, (dis)affiliation and face. Journal of Pragmatics 42(8). 2106-2119.

Haugh, Michael. 2010b. Co-constructing what is said in interaction. In Enikö Németh T. \& Károly Bibok (eds.), The Role of Data at the Semantics-Pragmatics Interface, 349-380. Berlin: Mouton de Gruyter.

Haugh, Michael. 2011. Humour, face and im/politeness in getting acquainted. In Bethan Davies, Michael Haugh \& Andrew Merrison Situated Politeness, 165184. London: Continuum.

Haugh, Michael. 2012. Conversational interaction. In Keith Allan \& Kasia M. Jaszczolt (eds.), The Cambridge Handbook of Pragmatics, 251-274. Cambridge: Cambridge University Press.

Haugh, Michael. in press a. Implicature, inference and cancellability. In Alessandro Capone, Franco Lo Piparo \& Marco Carapezza (eds.), Perspectives on Pragmatics and Philosophy. New York: Springer.

Haugh, Michael. in press b. Inference and implicature. In Carole Chappelle (ed.), The Encyclopedia of Applied Linguistics. Malden, MA: Wiley-Blackwell.

Haugh, Michael, \& Kasia M. Jaszczolt. 2012. Speaker intentions and intentionality. In Keith Allan \& Kasia M. Jaszczolt (eds.), The Cambridge Handbook of Pragmatics, 87-112. Cambridge: Cambridge University Press.

Heinemann, Trine. 2006. "Will you or can't you?" Displaying entitlement in interrogative requests. Journal of Pragmatics 38. 1081-1104.

Heritage, John. 1984. Garfinkel and Ethnomethodology. Cambridge: Polity Press.

Horn, Laurence R. 2012. Implying and inferring. In Keith Allan \& Kasia M. Jaszczolt (eds.), The Cambridge Handbook of Pragmatics, 69-86. Cambridge: Cambridge University Press.

Jaszczolt, Kasia M, \& Keith Allan eds. 2011. Salience and Defaults in Utterance Processing. Berlin: Mouton de Gruyter.

Jefferson, Gail. 1979. A technique for inviting laughter and its subsequent acceptancedeclination. In George Psathas (ed.), Everyday Language. Studies in Ethnomethodology, 79-95. New York: Irvington. 
Jefferson, Gail. 1993. Caveat speaker: preliminary notes on recipient topic-shift implicature. Research on Language and Social Interaction 26(1). 1-30.

Jefferson, Gail. 2004. Glossary of transcript symbols with an introduction. In Gene Lerner (ed.), Conversation Analysis: Studies from the First Generation, 13-23. Amsterdam: John Benjamins.

Kecskes, Istvan. 2010. The paradox of communication. Socio-cognitive approach to pragmatics. Pragmatics and Society 1(1). 50-73.

Keltner, Dacher, Lisa Capps, Ann Kring, Randall Young, \& Erin Heerey. 2001. Just teasing: a conceptual analysis and empirical review. Psychological Bulletin 127. 229-248.

Knobe, Joshua. 2010. Person as scientist, person as moralist. Behavioural and Brain Sciences 33. 315-365.

Levinson, Stephen. 1983. Pragmatics. Cambridge: Cambridge University Press.

Levinson, Stephen. 1995. Three levels of meaning. In Grammar and Meaning. Essays in Honour of Sir John Lyons, ed. F. Palmer, 90-115. Cambridge: Cambridge University Press.

Levinson, Stephen. 2000. Presumptive Meanings. The Theory of Generalised Conversational Implicature. Cambridge, Mass: MIT Press.

Levinson, Stephen. 2006a. Cognition at the heart of human interaction. Discourse Studies 8(1). 85-93.

Levinson, Stephen. 2006b. On the human 'interaction engine'. In Nick Enfield \& Stephen Levinson Roots of Human Sociality. Culture, Cognition and Interaction, 39-69. Oxford: Berg.

Levinson, Stephen. 2011. Multi-action turns. In 12th International Pragmatics Association Conference. Manchester, UK.

Levinson, Stephen. forthcoming. Action formation and ascription. In Tanya Stivers \& Jack Sidnell (eds.), Handbook of Conversation Analysis. Malden, MA: WileyBlackwell.

Liddicoat, Anthony. 2007. An Introduction to Conversation Analysis. London: Continuum.

Maynard, Douglas, \& Don Zimmermann. 1984. Topical talk, ritual and the social organization of relationships. Social Psychology Quarterly 47. 301-316.

Morency, Patrick, Steve Oswald, \& Louis de Saussure. 2008. Explicitness, implicitness and commitment attribution: a cognitive pragmatic perspective. Belgian Journal of Linguistics 22(1). 197-219.

Németh T., Enikö. 2008. Verbal information transmission without communicative intention. Intercultural Pragmatics 5(2):153-176.

Noordzij, Matthijs, Sarah Newman-Norlund, Jan Peter de Ruiter, Peter Hagoort, Stephen Levinson, Ivan Toni. 2010. Neural correlates of intentional communication. Frontiers in Human Neuroscience 4(188). 1-7.

Pacherie, Elisabeth. 2007. Is collective intentionality really primitive? In Carlo Penco, Michael Beaney \& Massimiliano Vignolo (eds.), Explaining the Mental: Naturalist and Non-naturalist Approaches to Mental Acts and Processes, 153175. Newcastle-on-Tyne: Cambridge Scholars Press.

Pomerantz, Anita. 1988. Offering a candidate answer: an information seeking strategy. Communication Monographs 55. 360-373.

Ruhi, Şükriye. 2007. Higher-order intentions and self-politeness in evaluations of (im)politeness: the relevance of compliment responses. Australian Journal of Linguistics 27(2). 107-145.

Sacks, Harvey. [1964]1992. Lectures on Conversation. Part I. Oxford: Blackwell. 
Schegloff, Emanuel. 1987. Some sources of misunderstanding in talk-in-interaction. Linguistics 25(1). 201-218.

Schegloff, Emanuel. 1990. On the organization of sequences as a source of "coherence" in talk-in-interaction. In Bruce Dorval (ed.), Conversational Organization and its Development, 51-77. Norwood, NJ: Ablex Publishing.

Schegloff, Emanuel. 1991. Conversation analysis and socially shared cognition. In Lauren Resnick, John Levine \& Stephanie Teasley (eds.), Perspectives on Socially Shared Cognition, 150-171. Washington, D.C.: American Psychological Association.

Schegloff, Emanuel. 1992. Repair after next turn: the last structurally provided defense of intersubjectivity in conversation. American Journal of Sociology 97(2). 1295-1345.

Schegloff, Emanuel. 2006. On possibles. Discourse Studies 8(1). 141-157.

Schegloff, Emanuel. 2007. Sequence Organization in Interaction. Cambridge: Cambridge University Press.

Schenkein, James. 1972. Towards an analysis of natural conversation and the sense of heheh. Semiotica 6. 344-377.

Searle, John. 1983. Intentionality. Cambridge: Cambridge University Press.

Searle, John. 1990. Collective intentions and actions. In Phillip Cohen, Jerry Morgan \& Martha Pollack Intentions in communication, 401-416. Cambridge, MA: MIT Press.

Searle, John. 2007. What is language: some preliminary remarks. In Istvan Kecskes \& Laurence Horn (eds.), Explorations in Pragmatics. Linguistic, Cognitive and Intercultural Aspects, 7-37. Berlin: Mouton de Gruyter.

Svennevig, Jan. 1999. Getting Acquainted in Conversation. Amsterdam: John Benjamins.

Taillard, Marie-Odile. 2003. Beyond communicative intention. UCL Working Papers in Linguistics 15. 189-206.

Tuomela, Raimo, \& Kaarlo Miller. 1988. We-intentions. Philosophical Studies 53. 367-389.

Uleman, James S, Saribay, S Adil, and Gonzalez, Celia M. 2008. Spontaneous inferences, implicit impressions, and implicit theories. Annual Review of Psychology 59:329-360.

Wedgwood, Daniel. 2011. The individual in interaction: why cognitive and discourselevel pragmatics need not conflict. Intercultural Pragmatics 8(4). 517-542.

\section{Appendix: Transcription conventions (following Jefferson 2004)}

\begin{tabular}{|c|c|}
\hline [ ] & overlapping speech \\
\hline$(0.5)$ & numbers in brackets indicate pause length \\
\hline (.) & micropause \\
\hline : & elongation of vowel or consonant sound \\
\hline . & word cut-off \\
\hline & falling or final intonation \\
\hline ? & rising intonation \\
\hline i & falling then rising intonation \\
\hline & 'continuing' intonation \\
\hline & latched utterances \\
\hline underlining & contrastive stress or emphasis \\
\hline CAPS & markedly louder \\
\hline
\end{tabular}


$\circ 0$

markedly soft

Hhh in-breathing

$\downarrow \uparrow$

sharp falling/rising intonation

hearably smiling voice

talk is compressed or rushed

talk is markedly slowed or drawn out

blank space in parentheses indicates uncertainty about the transcription 